\title{
The Role of Non-Structural Protein NSs in the Pathogenesis of Severe Fever with Thrombocytopenia Syndrome
}

\author{
Jumana Khalil ${ }^{1,2}$, Hiroki Kato ${ }^{1,3}$ and Takashi Fujita ${ }^{1,2, *}$ \\ 1 Laboratory of Virus Immunology, Institute for Frontier Life and Medical Science, Kyoto University, \\ Kyoto 606-8507, Japan; jumana.atkhalil.86c@st.kyoto-u.ac.jp (J.K.); hkato@uni-bonn.de (H.K.) \\ 2 Laboratory of Molecular and Cellular Immunology, Graduate School of Biostudies, Kyoto University, \\ Kyoto 606-8507, Japan \\ 3 Institute of Cardiovascular Immunology, University Hospital Bonn, University of Bonn, \\ 53127 Bonn, Germany \\ * Correspondence: tfujita@infront.kyoto-u.ac.jp; Tel.: +81-75-751-4031
}

Citation: Khalil, J.; Kato, H.; Fujita, T. The Role of Non-Structural Protein NSs in the Pathogenesis of Severe Fever with Thrombocytopenia Syndrome. Viruses 2021, 13, 876. https://doi.org/10.3390/v13050876

Academic Editor: Masayuki Saijo

Received: 15 April 2021

Accepted: 6 May 2021

Published: 11 May 2021

Publisher's Note: MDPI stays neutral with regard to jurisdictional claims in published maps and institutional affiliations.

Copyright: (c) 2021 by the authors. Licensee MDPI, Basel, Switzerland. This article is an open access article distributed under the terms and conditions of the Creative Commons Attribution (CC BY) license (https:// creativecommons.org/licenses/by/ $4.0 /)$.

\begin{abstract}
Viral non-structural proteins, such as NSs of the newly emerging severe fever with thrombocytopenia syndrome virus, are well established virulence factors, mediating viral pathogenesis and disease progression through various mechanisms. NSs has been described as a potent interferon antagonist and NF-kB agonist, two divergent signaling pathways in many immune responses upon a viral encounter. In this review, we highlight the many mechanisms used by NSs on the host that promote viral replication and hyper-inflammation. Understanding these host-pathogen interactions is crucial for antiviral therapy development.
\end{abstract}

Keywords: SFTSV NSs; NF-кB; cytokine storm; TBK1; viral pathogenesis; interferons; innate immunity

\section{Introduction}

Severe fever with thrombocytopenia syndrome virus (SFTSV), also recently called Dabie virus (DABV), is a newly discovered banyangvirus in the family Phenuiviridae [1]. It causes severe viral hemorrhagic fever with a mortality rate as high as 30\% [2,3]. SFTSV infection is often characterized by acute fever, myalgia, and gastrointestinal symptoms. These symptoms are accompanied by thrombocytopenia and leukocytopenia, which cause bleeding and have severe consequences. In response to this heavy disease burden, in addition to the lack of efficient vaccine or treatment, the World Health Organization lists SFTSV as one of the top prioritized pathogens for research and development for effective treatment [4]. The high fatality rate can be attributed to virus-induced cytokine storms, coagulopathies caused by disseminated intravascular coagulation, and the progression of multi-organ dysfunction to multi-organ failure [5,6].

The non-structural protein NSs, which is encoded by the small segment of the SFTSV ambisense genome, is the main virulence factor for the virus. NSs was shown to control innate immune responses of the host and to facilitate viral replication. These observations suggest that NSs plays an important role in the disease progression.

Although our understanding of the host-virus interactions and pathogenesis of SFTSV is limited, many studies have investigated these mechanisms and the development of antiviral measures. In this review, we provide a collective picture of the role of NSs in SFTSV infection.

\section{Influence of NSs on Innate Immunity}

\subsection{Induction of Interferon}

Interferons (IFNs) are secreted cytokines that play various roles in innate and adaptive immune responses and classified into three types: I, II, and III [7]. IFNs represent the first 
line of defense against invading viral pathogens. Type I IFNs are characterized by their strong antiviral activities, which limit viral replication and spread. Type II IFNs also share antiviral activities, but these are more prominent in immune responses against bacteria and parasites $[7,8]$. The receptors of type I and II IFNs are ubiquitously expressed; however, the expression of type III IFN receptors is tissue-specific. Normally the expression of type I and III IFN genes are suppressed, but they are induced by viral infection.

Intracellular and endosomal pattern recognition receptors, such as RIG-I-like receptors (RLRs) and toll-like receptors (TLRs), recognize viral RNA and trigger downstream signaling that ultimately results in the expression of IFNs and inflammatory cytokines [9]. In the case of SFTSV, RIG-I was shown to be the main receptor detecting the viral genome in the cytoplasm of infected cells. TLR3 also participates in SFTSV recognition, but MDA-5 contributes only minimally to this function [10,11]. Downstream of RIG-I and TLR-3, MAVS and TRIF, respectively, mediate the induction of IFN through TBK1 and IкB kinase (IKK) activation [12]. The anti-IFN function of NSs was first described in 2012 [13]. However, the mechanism behind IFN antagonism is still being investigated, although SFTSV NSs may disrupt the IFN pathway at multiple steps [11-16]. SFTSV NSs has the unique property of forming cytoplasmic granules, in which NSs entraps several host proteins and factors, blocking their functions. The E3 ubiquitin ligase TRIM25 is entrapped by NSs, hindering the TRMI25-mediated ubiquitination of RIG-I, a step required for its activation, and inhibiting the antiviral IFN production at the early level of PRR [11]. Additionally, the critical protein kinase TBK1 is physically trapped into the NSs granule, thus activation of IRF-3 is blocked [14]. Whether SFTSV also directs its antagonism against IRF7-mediated IFN- $\alpha$ production was also addressed. IRF-7 interacts directly with NSs in transfected and SFTSV-infected cells [12]. Collectively, NSs is a strong inhibitor of IFN production.

Notably, NSs interaction with TBK1 was also reported in mice [15], but not yet in other species. In contrast, STAT2 antagonism by NSs is absent in mice [15]. It will be merited if future research addresses species-specific functions of NSs protein.

\subsection{Action of Interferon}

Type I and III IFNs share a common signaling pathway, culminating in the activation of IFN-stimulated gene factor 3 (ISGF3), a heterotrimer consisting of the signal transducer and activator of transcription 1 (STAT1) and STAT2 heterodimer and IFN regulatory factor 9 (IRF-9). ISGF3 transcriptionally regulates numerous IFN-stimulated genes (ISGs) that encode a wide range of antiviral proteins to establish an antiviral state. Type II IFN signaling, however, involves STAT1 homodimers as the downstream transcription complex. Thus, while STAT1 protein is required for the induction of all types of IFNs, STAT2 is not involved in type II IFN-induced signaling. NSs directly interacts with STAT2 and sequesters it into NSs granules [16]. The interaction of STAT1 with NSs is controversial [17-19], as is the role of type II IFN in anti-SFTSV function $[18,20,21]$. Figure 1 summarizes the viral induction of type I and III IFN production and action, and the NSs antagonism. 


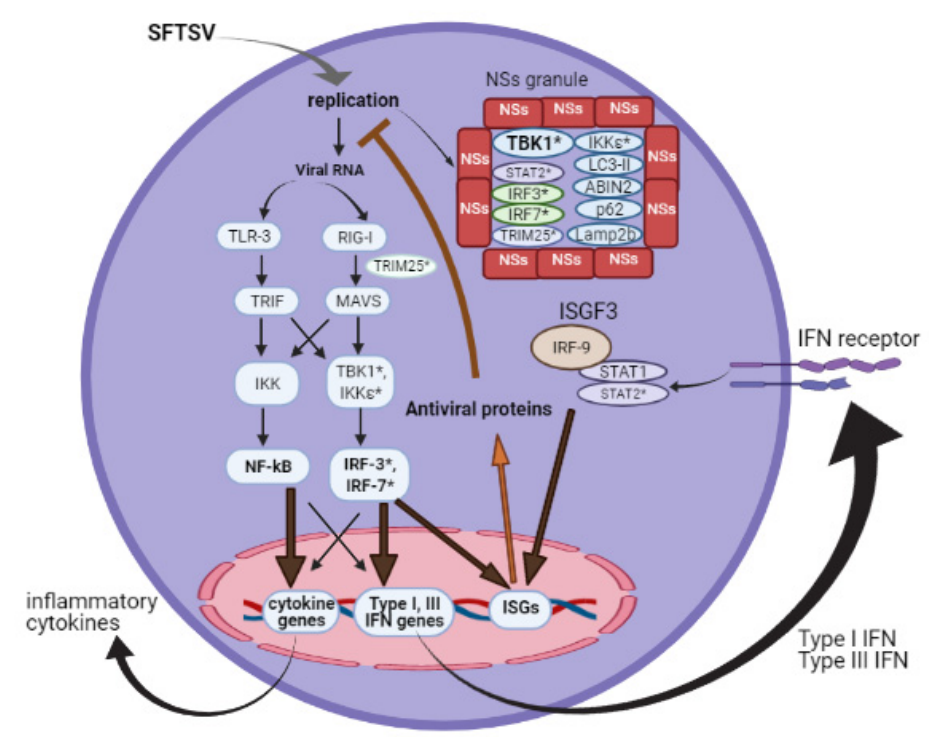

Figure 1. Type I IFN antagonism by SFTSV NSs. In virus-infected cells, various viral RNA species are sensed by TLR3 and RLR to initiate a signaling cascade for antiviral responses. NSs protein can intrinsically form cytoplasmic granules that entrap several factors involved in antiviral responses (* indicates such factors).

\subsection{Non-IFN Antiviral Responses}

Autophagy has divergent roles in viral infections; depending on the virus, it may restrict or enhance viral replication [22].

Preliminary results concerning SFTSV and autophagy have been reported. The autophagy-related protein LC3-II negatively regulates SFTSV replication [23]. NSs interacts with LC3-II and co-localizes with the autophagy marker p62 and the autolysosome marker Lamp2b [23,24]. p62 is a substrate for TBK1 [25], which is implicated in autophagy regulation. It is also reported that NSs enhances p62 stability and oligomerization by inhibiting tripartite motif 21 (TRIM21) [24]. However, the role of autophagy in SFTSV infection has not been clarified.

\subsection{Role of NSs in Viral Replication}

It has been hypothesized that SFTSV NSs is directly involved in viral RNA replication by acting as a scaffold protein, forming a platform, which may be critical in host-virus interactions, as well as viral replication. The group named this platform viroplasm-like structures (VLS), referring to the microscopic cytoplasmic granules formed by SFTSV NSs [26], and the replication complex consists of a lipid droplet-based structure [26,27]. Cell cycle arrest through a NSs/cyclin-dependent kinase 1 (CDK1) interaction may enhance SFTSV replication [28].

\section{SFTSV Infection Mouse Models}

SFTSV infection is not fatal in wild-type (WT) mice, but it is in mice deficient of type I IFN receptor (Ifnar1-/-) [29]. This effect is consistent with type I IFN being a strong barrier against the virus. However, this assumption ignores the fact that SFTSV encodes NSs, a potent antagonist against type I IFN responses. Therefore, the mechanism of the fatal SFTSV infection in Ifnar 1-/ - mice is not simple. Indeed, the expression of inflammatory cytokines and chemokines is markedly enhanced in Ifnar 1-/ - compared with WT mice [10]. Notably, Mavs - / - and Myd88-/ - mice, which exhibit impaired type I IFN and inflammatory cytokine production, show comparable survival to WT mice against SFTSV infection. These results strongly suggest that hyper-inflammation, or a cytokine storm, is responsible for the fatal outcome of the infection, although a mechanistic link between the lack of IFNAR1 and the hyper-inflammation remains to be investigated. 


\section{Cytokine Storm Induction}

The induction of a cytokine storm by SFTSV was described shortly after the virus was first identified. SFTS patients, especially fatal cases, exhibit abnormally high cytokine levels in their sera, which correlates with multi-organ damage and poor prognosis. Elevated cytokines include pro-inflammatory mediators such as tumor necrosis factor- $\alpha$ (TNF- $\alpha$ ), interleukin-6 (IL-6), C-X-C motif ligand 10 (CXCL10), and monocyte chemoattractant protein $[20,21,30-33]$. These results are consistent with SFTSV infection in Ifnar1-/mice [10]. The hyper-inflammation seen in the mouse model was characterized by an enhanced production of proinflammatory cytokines and chemokines at the mRNA level, including CXCL1, CCL2, CCL3, TNF- $\alpha$, IL-1 $\beta$ and IL-6 genes.

NSs expression in vitro, in conjugation with double-stranded RNA or the virusinduced signal, augmented the induction of pro- and anti-inflammatory cytokines, a response reminiscent of a cytokine storm [32,33], suggesting that SFTSV induces the cytokine storm through NSs [32]. It has been recently shown that NF- $\mathrm{kB}$ may be the primary transcription factor mediating the NSs-induced cytokine upregulation and that controlling NF- $\mathrm{BB}$ activity may be a therapeutic approach to treat SFTS [32]. The study revealed that TBK1 has intrinsic inhibitory activity for IKK $\beta$, a component of the IKK complex. Genetic deletion or the pharmacological inhibition of TBK1 resulted in the hyper-activation of NF- $k B$. Because NSs is a strong inhibitor of TBK1, its expression resulted in the release of NF- $\mathrm{KB}$ from TBK1 suppression. The function of NSs in IFN response suppression and hyper-inflammation is summarized in Figure 2. Studies in vivo and in vitro have highlighted TBK1 as a critical regulator of the anti-viral and inflammatory responses upon SFTSV infection. These results suggest the suppression of NF- $\mathrm{kB}$ as a promising therapy for SFTS $[10,32]$.

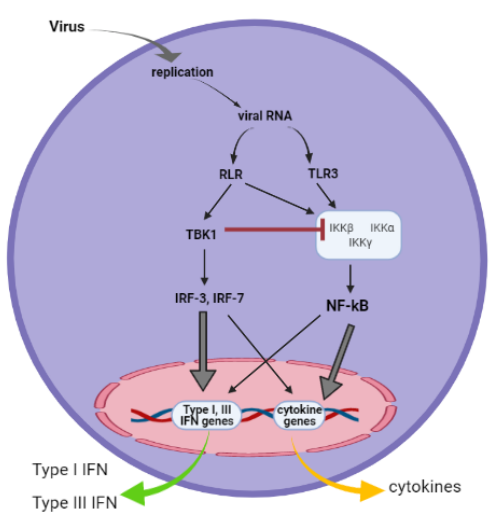

(A)

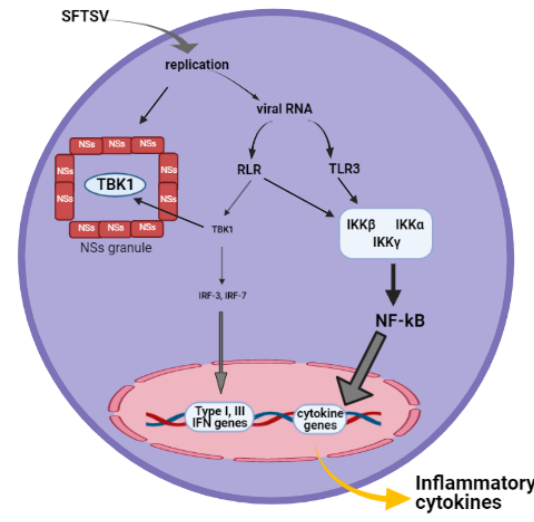

(B)

Figure 2. NSs induction of an NF-kB-mediated cytokine storm. (A) In virus-infected cells, viral RNA sensing activates TBK1, which activates IRF-3 for the transcriptional activation of type I IFN and cytokine genes. TBK1 negatively regulates the IKK complex by interacting with IKK $\beta$ to limit the inflammatory responses mediated by NF-кB. (B) Upon SFTSV infection, viral NSs granules sequester TBK1, resulting in impaired IFN production. This liberates IKK from the negative regulation of TBK1, leading to the hyper-activation of NF- $\mathrm{KB}$ and inflammatory responses.

Intriguingly, immune-suppressive cytokines are also upregulated throughout the course of SFTSV infection, and their upregulation is associated with disease severity. These anti-inflammatory cytokines include IL-10, IL-12, and IL-23 [34]. One report found that NSs interacts with ABIN2 (A20-binding inhibitor of NF- $\mathrm{KB}$ activation-2) to stabilize the TPL2 (tumor progression locus 2)-ABIN2-p105 ternary complex and activate the TPL2 signaling pathway, which promotes robust IL-10 expression [33]. The TPL2 signaling pathway is required for the SFTSV-induced lethal phenotype [33]. These findings, however, question whether the outcome of SFSV infection is immunopathological or immunosuppressive. 
Determining which outcome dominates the pathological scenario in human SFTS requires more study.

Another report linked the SFTSV-induced IL-10 upregulation to the expression of miR$146 \mathrm{~b}$, an endogenous non-coding RNA that modulates the expression of specific genes posttranscriptionally. MiR-146b targets STAT1 to skew macrophage differentiation into antiinflammatory M2 type during the late stages of the infection [35]. SFTSV replicates higher in the presence of M2 than in M1 [35]; thus, this skewed differentiation of macrophages may have an important role in the pathogenesis of SFTSV.

\section{Conclusions}

In this review, we addressed recent progress in host responses against SFTSV and the role of the main virulence factor for this virus, NSs, in the viral pathogenesis. We explain how NSs aggravates the disease progression by interacting with host proteins inside NSsformed cytoplasmic granules. NSs interacts with TBK1, leading to the suppression of antiviral IFN production and a hyper-activation that causes pro-inflammatory cytokine storms. This effect gives the virus a state of uncontrolled replication inside its target hematopoietic cells. NSs also interacts with several other proteins (summarized in Table 1) inside the granules to manipulate immune signaling pathways and evade anti-viral responses. This characteristic of SFTSV NSs is unique and has not been reported among other Phenuiviridae. Comparably, NSs protein of Rift Valley fever virus (RVFV NSs) assembles into nuclear and cytosolic aggregates in infected cells. In the nucleus, it forms filamentous structure. While in the cytosol, amorphous granules are observed [36,37].

Table 1. List of host proteins to which NSs interacts.

\begin{tabular}{cc}
\hline Protein & Effect of Interaction \\
\hline TBK1 & Suppressed IFN responses and activated NF- $\mathrm{kB}$ signaling [14,32] \\
LC3-II & Promoted viral replication and autophagy regulation during SFTSV infection [23] \\
TRIM25 & Inhibited ubiquitination and activation of RIG-I [11] \\
IRF3 & Inhibited transcription of IFN-I [14] \\
IRF7 & Inhibited transcription of IFN-I [12] \\
STAT2 & Suppressed IFN responses [14] \\
IKK $\varepsilon$ & Cell cycle arrest at G2/M transition [28] \\
CDK1 & Suppressed JAK/STAT signaling and abrogated ISG production [16,17] \\
pBIN2 & Activated TPL2 signaling and IL-10 production [33] \\
Lamp2b & Unknown role in autophagy regulation [24] \\
\hline
\end{tabular}

Notably, other effects of SFTSV on host cell machinery have been reported. However, the role of NSs in such interference is not yet identified. For example, SFTSV triggers mitochondrial dysfunction and NLRP3 inflammasome activation [38]. Moreover, the virus activates p38 mitogen-activated protein kinase (MAPK) signaling pathway [39], which plays a crucial role in many biological processes, such as cell proliferation and apoptosis, inflammation, aging and tumorigenesis [40-42]. Additionally, SFTSV causes a global disruption of naïve T-cell differentiation, and antibody class switching [34], resulting in impeded humoral immune responses. Whether NSs is the viral component regulating such effects is worth investigating in the future.

In conclusion, NSs is the virulent factor for SFTSV that mediates numerous pathological processes in the host. Based on its role in the pathogenesis of SFTSV, we envision a therapy directed specifically against NSs to alleviate the syndrome.

Author Contributions: J.K., H.K. and T.F. contributed to writing and revising the review paper. All authors have read and agreed to the published version of the manuscript.

Funding: This work was supported by research grants from the Japan Agency for Medical Research and Development (Research Program on Emerging and Re-emerging Infectious Diseases 
[jp19fk0108081h1001, jp20fk0108081h1202, jp21fk0108081h1203]) and from the Japan Society for the Promotion of Science, Fund for the Promotion of Joint International Research, Fostering Joint International Research [B] [18KK0232]).

Institutional Review Board Statement: Not applicable.

Informed Consent Statement: Not applicable.

Data Availability Statement: Not applicable.

Acknowledgments: The authors would also like to acknowledge the contribution of Grant-in-Aid for Scientific Research B [18H02344].

Conflicts of Interest: The authors declare no conflict of interest.

\section{References}

1. Abudurexiti, A.; Adkins, S.; Alioto, D.; Alkhovsky, S.V.; Avšič-Županc, T.; Ballinger, M.J.; Bente, D.A.; Beer, M.; Bergeron, É.; Blair, C.D.; et al. Taxonomy of the order Bunya-virales: Update 2019. Arch. Virol. 2019, 164, 1949-1965. [CrossRef] [PubMed]

2. Zhan, J.; Wang, Q.; Cheng, J.; Hu, B.; Li, J.; Zhan, F.; Song, Y.; Guo, D. Current status of severe fever with thrombocytopenia syndrome in China. Virol. Sin. 2017, 32, 51-62. [CrossRef] [PubMed]

3. Kato, H.; Yamagishi, T.; Shimada, T.; Matsui, T.; Shimojima, M.; Saijo, M.; Oishi, K. Epidemiological and Clinical Features of Severe Fever with Thrombocytopenia Syndrome in Japan, 2013-2014. PLoS ONE 2016, 11, e0165207. [CrossRef] [PubMed]

4. Word Health Organization (WHO). Annual Review of Diseases Prioritized under the Research and Development Blueprint. 2017. Available online: http:/ / www.who.int/csr/research-and-development/en/ (accessed on 2 July 2019).

5. Saijo, M. Pathophysiology of severe fever with thrombocytopenia syndrome and development of specific antiviral therapy. $J$. Infect. Chemother. 2018, 24, 773-781. [CrossRef]

6. Reece, L.M.; Beasley, D.W.; Milligan, G.N.; Sarathy, V.V.; Barrett, A.D. Current status of Severe Fever with Thrombocytopenia Syndrome vaccine development. Curr. Opin. Virol. 2018, 29, 72-78. [CrossRef]

7. Lin, F.-C.; Young, H.A. Interferons: Success in anti-viral immunotherapy. Cytokine Growth Factor Rev. 2014, 25, 369-376. [CrossRef] [PubMed]

8. Zhang, S.Y.; Boisson-Dupuis, S.; Chapgier, A.; Yang, K.; Bustamante, J.; Puel, A.; Picard, C.; Abel, L.; Jouanguy, E.; Casanova, J.L. Inborn errors of interferon (IFN)-mediated immunity in humans: Insights into the respective roles of IFN-alpha/beta, IFN-gamma, and IFN-lambda in host defense. Immunol. Rev. 2008, 226, 29-40. [CrossRef]

9. Yoo, J.-S.; Kato, H.; Fujita, T. Sensing viral invasion by RIG-I like receptors. Curr. Opin. Microbiol. 2014, 20, 131-138. [CrossRef]

10. Yamada, S.; Shimojima, M.; Narita, R.; Tsukamoto, Y.; Kato, H.; Saijo, M.; Fujita, T. RIG-I-Like Receptor and Toll-Like Receptor Signaling Pathways Cause Aberrant Production of Inflammatory Cytokines/Chemokines in a Severe Fever with Thrombo-cytopenia Syndrome Virus Infection Mouse Model. J. Virol. 2018, 92, e02246-17. [CrossRef]

11. Min, Y.-Q.; Ning, Y.-J.; Wang, H.; Deng, F. A RIG-I-like receptor directs antiviral responses to a bunyavirus and is antagonized by virus-induced blockade of TRIM25-mediated ubiquitination. J. Biol. Chem. 2020, 295, 9691-9711. [CrossRef]

12. Hong, Y.; Bai, M.; Qi, X.; Li, C.; Liang, M.; Li, D.; Cardona, C.J.; Xing, Z. Suppression of the IFN- $\alpha$ and $-\beta$ Induction through Sequestering IRF7 into Viral Inclusion Bodies by Nonstructural Protein NSs in Severe Fever with Thrombocytopenia Syndrome Bunyavirus Infection. J. Immunol. 2019, 202, 841-856. [CrossRef]

13. Qu, B.; Qi, X.; Wu, X.; Liang, M.; Li, C.; Cardona, C.J.; Xu, W.; Tang, F.; Li, Z.; Wu, B.; et al. Suppression of the interferon and NF- $\kappa \mathrm{B}$ responses by severe fever with thrombocytopenia syndrome virus. J. Virol. 2012, 86, 8388-8401. [CrossRef]

14. Wu, X.; Qi, X.; Qu, B.; Zhang, Z.; Liang, M.; Li, C.; Cardona, C.J.; Li, D.; Xing, Z. Evasion of antiviral immunity through sequestering of TBK1/IKKع/IRF3 into viral inclusion bodies. J. Virol. 2014, 88, 3067-3076. [CrossRef] [PubMed]

15. Yoshikawa, R.; Sakabe, S.; Urata, S.; Yasuda, J. Species-Specific Pathogenicity of Severe Fever with Thrombocytopenia Syn-drome Virus Is Determined by Anti-STAT2 Activity of NSs. J. Virol. 2019, 93. [CrossRef] [PubMed]

16. Kitagawa, Y.; Sakai, M.; Shimojima, M.; Saijo, M.; Itoh, M.; Gotoh, B. Nonstructural protein of severe fever with thrombocyto-penia syndrome phlebovirus targets STAT2 and not STAT1 to inhibit type I interferon-stimulated JAK-STAT signaling. Microbes Infect. 2018, 20, 360-368. [CrossRef] [PubMed]

17. Ning, Y.-J.; Feng, K.; Min, Y.-Q.; Cao, W.-C.; Wang, M.; Deng, F.; Hu, Z.; Wang, H. Disruption of type I interferon signaling by the nonstructural protein of severe fever with thrombocytopenia syndrome virus via the hijacking of STAT2 and STAT1 into inclusion bodies. J. Virol. 2015, 89, 4227-4236. [CrossRef] [PubMed]

18. Ning, Y.-J.; Mo, Q.; Feng, K.; Min, Y.-Q.; Li, M.; Hou, D.; Peng, C.; Zheng, X.; Deng, F.; Hu, Z.; et al. Interferon- $\gamma$-Directed Inhibition of a Novel High-Pathogenic Phlebovirus and Viral Antagonism of the Antiviral Signaling by Targeting STAT1. Front. Immunol. 2019, 10, 1182. [CrossRef]

19. Rezelj, V.V.; Li, P.; Chaudhary, V.; Elliott, R.M.; Jin, D.Y.; Brennan, B. Differential Antagonism of Human Innate Immune Re-sponses by Tick-Borne Phlebovirus Nonstructural Proteins. mSphere 2017, 2, e00234-17. [CrossRef]

20. Deng, B.; Zhang, S.; Geng, Y.; Zhang, Y.; Wang, Y.; Yao, W.; Wen, Y.; Cui, W.; Zhou, Y.; Gu, Q.; et al. Cytokine and Chemokine Levels in Patients with Severe Fever with Thrombocytopenia Syndrome Virus. PLoS ONE 2012, 7, e41365. [CrossRef] [PubMed] 
21. Kwon, J.-S.; Kim, M.-C.; Kim, J.Y.; Jeon, N.-Y.; Ryu, B.-H.; Hong, J.; Chong, Y.P.; Lee, S.-O.; Choi, S.-H.; Kim, Y.S.; et al. Kinetics of viral load and cytokines in severe fever with thrombocytopenia syndrome. J. Clin. Virol. 2018, 101, 57-62. [CrossRef]

22. Choi, Y.; Bowman, J.W.; Jung, J.U. Autophagy during viral infection-A double-edged sword. Nat. Rev. Microbiol. 2018, 16, 341-354. [CrossRef] [PubMed]

23. Sun, Y.; Liu, M.-M.; Lei, X.-Y.; Yu, X.-J. SFTS phlebovirus promotes LC3-II accumulation and nonstructural protein of SFTS phlebovirus co-localizes with autophagy proteins. Sci. Rep. 2018, 8, 1-11. [CrossRef] [PubMed]

24. Choi, Y.; Jiang, Z.; Shin, W.-J.; Jung, J.U. Severe Fever with Thrombocytopenia Syndrome Virus NSs Interacts with TRIM21 To Activate the p62-Keap1-Nrf2 Pathway. J. Virol. 2020, 94. [CrossRef]

25. Pilli, M.; Arko-Mensah, J.; Ponpuak, M.; Roberts, E.; Master, S.; Mandell, M.A.; Dupont, N.; Ornatowski, W.; Jiang, S.; Bradfute, S.B.; et al. TBK-1 promotes autophagy-mediated anti-microbial defense by controlling autophagosome maturation. Immunity 2012, 37, 223-234. [CrossRef]

26. Sun, Q.; Qi, X.; Zhang, Y.; Wu, X.; Liang, M.; Li, C.; Li, D.; Cardona, C.J.; Xing, Z. Synaptogyrin-2 Promotes Replication of a Novel Tick-borne Bunya-virus through Interacting with Viral Nonstructural Protein NSs. J. Biol. Chem. 2016, 291, 16138-16149. [CrossRef] [PubMed]

27. Wu, X.; Qi, X.; Liang, M.; Li, C.; Cardona, C.J.; Li, D.; Xing, Z. Roles of viroplasm-like structures formed by nonstructural protein NSs in infection with severe fever with thrombocytopenia syndrome virus. FASEB J. 2014, 28, 2504-2516. [CrossRef] [PubMed]

28. Liu, S.; Liu, H.; Kang, J.; Xu, L.; Zhang, K.; Li, X.; Hou, W.; Wang, Z.; Wang, T. The Severe Fever with Thrombocytopenia Syndrome Virus NSs Protein Interacts with CDK1 To Induce G2 Cell Cycle Arrest and Positively Regulate Viral Replication. J. Virol. 2020, 94. [CrossRef] [PubMed]

29. Liu, Y.; Wu, B.; Paessler, S.; Walker, D.H.; Tesh, R.B.; Yu, X.J. The pathogenesis of severe fever with thrombocytopenia syndrome virus infection in alpha/beta interferon knockout mice: Insights into the pathologic mechanisms of a new viral hemor-rhagic fever. J. Virol. 2014, 88, 1781-1786. [CrossRef]

30. Sun, Y.; Jin, C.; Zhan, F.; Wang, X.; Liang, M.; Zhang, Q.; Ding, S.; Guan, X.; Huo, X.; Li, C.; et al. Host Cytokine Storm Is Associated With Disease Severity of Severe Fever With Thrombocytopenia Syndrome. J. Infect. Dis. 2012, 206, 1085-1094. [CrossRef] [PubMed]

31. Ding, Y.-P.; Liang, M.-F.; Ye, J.-B.; Liu, Q.-H.; Xiong, C.-H.; Long, B.; Lin, W.-B.; Cui, N.; Zou, Z.-Q.; Song, Y.-L.; et al. Prognostic value of clinical and immunological markers in acute phase of SFTS virus infection. Clin. Microbiol. Infect. 2014, 20, O870-O878. [CrossRef]

32. Khalil, J.; Yamada, S.; Tsukamoto, Y.; Abe, H.; Shimojima, M.; Kato, H.; Fujita, T. The Non-structural Protein NSs of SFTSV Causes Cytokine Storm Through the Hyper-activation of NF-kB. Mol. Cell. Biol. 2020. [CrossRef] [PubMed]

33. Choi, Y.; Park, S.-J.; Sun, Y.; Yoo, J.-S.; Pudupakam, R.S.; Foo, S.-S.; Shin, W.-J.; Chen, S.B.; Tsichlis, P.N.; Lee, W.-J.; et al. Severe fever with thrombocytopenia syndrome phlebovirus non-structural protein activates TPL2 signalling pathway for viral immunopathogenesis. Nat. Microbiol. 2019, 4, 429-437. [CrossRef] [PubMed]

34. Song, P.; Zheng, N.; Liu, Y.; Tian, C.; Wu, X.; Ma, X.; Chen, D.; Zou, X.; Wang, G.; Wang, H.; et al. Deficient humoral responses and disrupted B-cell immunity are asso-ciated with fatal SFTSV infection. Nat. Commun. 2018, 9, 3328. [CrossRef]

35. Zhang, L.; Fu, Y.; Wang, H.; Guan, Y.; Zhu, W.; Guo, M.; Zheng, N.; Wu, Z. Severe Fever With Thrombocytopenia Syndrome Virus-Induced Macrophage Differentiation Is Regulated by miR-146. Front. Immunol. 2019, 10, 1095. [CrossRef] [PubMed]

36. Léger, P.; Nachman, E.; Richter, K.; Tamietti, C.; Koch, J.; Burk, R.; Kummer, S.; Xin, Q.; Stanifer, M.; Bouloy, M.; et al. NSs amyloid formation is associated with the virulence of Rift Valley fever virus in mice. Nat. Commun. 2020, 11, 3281. [CrossRef] [PubMed]

37. Struthers, J.K.; Swanepoel, R. Identification of a Major Non-structural Protein in the Nuclei of Rift Valley Fever Virus-infected Cells. J. Gen. Virol. 1982, 60, 381-384. [CrossRef]

38. Li, S.; Li, H.; Zhang, Y.-L.; Xin, Q.-L.; Guan, Z.-Q.; Chen, X.; Zhang, X.-A.; Li, X.-K.; Xiao, G.-F.; Lozach, P.-Y.; et al. SFTSV Infection Induces BAK/BAX-Dependent Mitochondrial DNA Release to Trigger NLRP3 Inflammasome Activation. Cell Rep. 2020, 30, 4370-4385.e7. [CrossRef]

39. Cheng, Y.; Sun, F.; Wang, L.; Gao, M.; Xie, Y.; Sun, Y.; Liu, H.; Yuan, Y.; Yi, W.; Huang, Z.; et al. Virus-induced p38 MAPK activation facilitates viral infection. Theranostics 2020, 10, 12223-12240. [CrossRef]

40. Raingeaud, J.; Gupta, S.; Rogers, J.S.; Dickens, M.; Han, J.; Ulevitch, R.J.; Davis, R.J. Pro-inflammatory Cytokines and Environmental Stress Cause p38 Mitogen-activated Protein Kinase Activation by Dual Phosphorylation on Tyrosine and Threonine. J. Biol. Chem. 1995, 270, 7420-7426. [CrossRef] [PubMed]

41. Han, J.; Lee, J.; Bibbs, L.; Ulevitch, R. A MAP kinase targeted by endotoxin and hyperosmolarity in mammalian cells. Science 1994, 265, 808-811. [CrossRef]

42. Chen, X.; Hao, A.; Li, X.; Ye, K.; Zhao, C.; Yang, H.; Ma, H.; Hu, L.; Zhao, Z.; Hu, L.; et al. Activation of JNK and p38 MAPK Mediated by ZDHHC17 Drives Glioblastoma Multiforme Development and Malignant Progression. Theranostics 2020, 10, 998-1015. [CrossRef] [PubMed] 